\title{
Pragmatism in China - Chinese pragmatism
}

\author{
TianCi Li ${ }^{1, a}$, YuLin $\mathrm{Wu}^{2, b}$ \\ ${ }^{1}$ Harbin university of science and technology, Harbin, 150001, China \\ ${ }^{2}$ Harbin university of science and technology, Harbin, 150001, China \\ a574054331@qq.com, ${ }^{\text {bwuyulin0501@163.com }}$
}

Keywords: pragmatism, traditional thoughts, pragmatism with Chinese style

\begin{abstract}
This paper is divided into 4 parts. 1. The embryo of "pragmatism" taking actual operation and practical as purpose formed under the Chinese traditional cultural thoughts. This paper gives examples to introduce the thinking model of pragmatic first in the ancient China and the impressive idea of "pragmatism", which we temporarily call as "ancient China pragmatism thoughts". 2. Development and dominant ideas of pragmatic philosophy in the west. Based on introduction of doctrines of Peirce, James, Dewey, et al, the process of the pragmatism in 20th century from sprout to being popular in the world is summarized. Discussion of the influence of James's view on pragmatism on the society and the world is made to draw the content of part 3. 3. "Contemporary China Pragmatic Thought" that formed in the reform and opening period blending in pragmatic philosophy in the west based on the traditional culture is characterized by history and era. Under special era background and objective condition, the pragmatic thoughts set down roots and blend in the traditional thoughts to produce chemical reaction. Therefore the new thoughts different from western pragmatic philosophy has formed and rapidly swept across the country to greatly influence the world view, value and moral code in China. 4. A comparison between western pragmatic philosophy and contemporary pragmatism is carried out to explain that the thoughts only bring short-term benefit to people rather than long-term one. It will bring negative factors in the long run.
\end{abstract}

What is pragmatism? Briefly, pragmatism be understood as a instrumentalism taking effectiveness as purpose and experiment as method. The word "pragmatism" is derived from Greek $\pi \rho \alpha \gamma \mu \alpha$

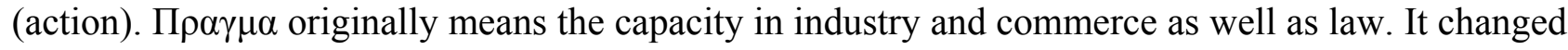
to the meaning of "pragmatic" through long-term evolution. Pragmatism was invented from the modern philosophy school in the U.S. in 1870s. It finally became the philosophy thoughts trend with the most significant influence in the U.S. at the turn of the twentieth century. The dominant thought stresses that practical experience should put in the first place while theory and logic are secondary. Stick to doing everything from the actual situation. Take the results as the standard to examine all the theories. The purpose is to directly solve the problems in real life. The method of pragmatism is a method to solve the metaphysics. It's characteristics is to utilize the positivism and stress "life" "action" and "effect". For the relationship between the action and thought, pragmatism takes action as the center rather than the thought. From this point, pragmatism has obvious characteristic of behaviorism. Therefore, it is called as philosophy of action or practical philosophy.

Although the concept of "pragmatic thought" and "pragmatism" exist in both China and the West, people have different comprehension of "pragmatic". Both thoughts are quite different in essence. "Pragmatism" with Chinese characteristics tends to obtain practical application operation and rapid 
result feedback, while "pragmatism" in the west stresses integrity and the further future. Fundamentally speaking, the concept of Chinese pragmatic thought and western pragmatism are entirely different from each other.

\section{I . Ancient China pragmatism thoughts under the Chinese traditional thinking model}

Under the Chinese traditional thinking model ancient China pragmatism thoughts is the valuable wealth inherited from the thousands of years Chinese civilization. China, Ancient India, Ancient Egypt and Ancient Babylon are known as "Four Great Ancient Civilizations". "Scientific" achievements in ancient China were very extraordinary. Many scientific discoveries and inventions were hundreds even thousands of years earlier than Europe. For example, the "seismograph" invented by Zhang Heng in the Eastern Han Dynasty can determine the direction of the earthquake taking place thousands miles away, which was 1700 years earlier than Europe. The book "Pi" written by $\mathrm{Zu}$ Chongzhi corrected the pi to seven decimal places based on the algorithm proposed by Liu Hui and kept the record for about one thousand years. However, most of these achievements and books were created to solve problems in the real life and provided direct experience and operation rather than systematic research of theories and rules.

The ancient Chinese science was applied science with experience as method and practical application as purpose. It lacked understanding and rational knowledge of different phenomenon in the nature. Chinese ancient science was practicable, which always aimed at meeting human actual demand. However, people only knew how to use the means but did not know the reasons. There are few theories summarized and analyzed with logical method. As everyone knows, Chinese invented gunpowder which was made into fireworks rather than guns. After several years, western powers took our ancestors' inventor knocked down out country's gate that was closed for thousands of years. Ancient Chinese science took the practicability as basis and served for production and domination consolidation, which determined that it is impossible to become the systematic scientific theory based on experimental results. Ancient Chinese science can be summarized as "paying more attention to experience, integration and practicality than experiment, analysis and theory".

\section{Development and Dominant Thought of West Pragmatism Philosophy}

Pragmatism is a philosophical school growing in the U.S., which is one of the most popular and influencing philosophical schools in the west. It was born in the U.S. in 1870s. The Metaphysical club of Harvard University was recognized as the first pragmatism organization in the world. The host of the club Peirce was regarded as the founder of pragmatism. Peirce mentioned the basic principle of pragmatism in "The Fixation of Belief " and "How to Make Our Ideas Clear " published respectively in 1877 and 1878. [2] Later the most important representative man William James in the history of pragmatism proposed the statement of pragmatism in his speech of "Philosophical Conceptions \& Practical Results" in California in 1898. He introduced the pragmatism into the theory of truth to form the view of truth of pragmatism. The pragmatism therefore became systematic theory. James published "Pragmatism" (1907) "A Pluralistic Universe" (1909) "Essays in Radical Empiricism” (1912), etc.[2] In James's theory, two points are stressed such as pragmatism and radical empiricism. Pragmatism pays more attention to practical experience than to logic, principle. He believed that action is superior to dogma, and experience is superior to rigidity. He proposed a new set of methodology for social sciences research. James's contribution lied in that he summarized a systematic pragmatism theory system from Peirce's 
abstract methodology principle of pragmatism and applied it in solving practical problems. However, it was Dewey who popularized the pragmatism. Compared to James, Dewey paid more attention to science, education and politics. According to Dewey, scientific theory and concept are not reflection of the objective reality, while it only was the assumption of application that could be proposed without considering any objective reality. Theories or concepts created by human are tools designed to achieve some purposes. If these tools helped people achieve the purpose, they would be truth. Truth does not lie in that it is true or false but that it is helpful or useless. Since Dewey's theory catered to the demand of the monopoly capitalist class at that time, he was accepted by them. West philosophy circle persisted different views on the new-developing school of pragmatism. The left wing theorists reckoned that it was created to promote the power politics of imperialism, while academism argued that it was too secular without critical thinking, so it could not be called as philosophy. In my opinion, although all of the above viewpoints are reasonable, they are still misleading. Pragmatism philosophy should be treated rationally. As Marx said, "Each kind of philosophy is the essence of of the spirit of its era." [3] Pragmatism philosophy could be spread up to now due to its strengths.

\section{Contemporary pragmatism with Chinese style with introduction of western thoughts in the reform and opening}

From the national level, China is the country that is most heavily affected by pragmatism. Due to different social formation and state system, western pragmatism can hardly survive under the socialist value outlook after the establishment of new China. The pragmatism mentioned at the beginning of this paper has nothing to do with western pragmatism. However, how did it set down roots and grow in China? It is because that it has been growing silently in daily life. Once people neglect thought and go away from philosophy, with the thought of quick benefits, it will naturally emerge and flourish. With the tide of reform and opening in 1979, supported by national policies, individual operation and private enterprises appeared on the historical stage and opened the curtain of acquiring wealth. People's living standard had increased significantly during 20 years from 1980 to 1999 , which was brought by the spirit of pragmatism. This spirit had made undeniable "contributions" for the economic development in the reform and opening era.

Experienced in the rapid growth of the economy in the early years of the reform, pragmatic economy development theory met a bottleneck after entering the new millennium. The theory that some people get better off earlier did not develop to the expected direction but resulted serious polarization in income distribution. The Gini coefficient reached a dangerous level. Under the international economic globalization, the economic equilibrium went far gradually while the balance of morality and material desire was tipped. Due to all the above phenomenon the pragmatism was dominant in the society.

As the western pragmatism kept balance in pursing current benefit and future development, they always acquire good social performance. The modern scientific system, market economy system and the democracy and freedom based on check-and-balance mechanism are the results of the pragmatism. Currently among the western countries, especially in the U.S., the representative of pragmatism, pragmatism plays a significant role in politics, education, science and society. The localized pragmatism drives various fields to develop in the U.S., which also is the a major factor supporting the dominance in the world.

Pragmatism with Chinese style has many hidden trouble in a long run although it seemed to save the time and improve efficiency in a short-term as people paying too much attention to the practical operating effect and present benefit. Although more than a few opportunists exist in the present 
society, we will inevitably face the difficulties of lack of available resources and system theories, which will be the inescapable reality for individual and society even the states and nations.

\section{References:}

[1] Pragmatism and the Spirit of Chinese Culture Zhao Dunhua;- " Philosophical Investigations"-2014-01-25

[2]Further Discussion of Pragmatism Truth Theory of James Rao Diqing- " Qilu Journal" $-2003-03-30$

[3]Pragmatism: the philosophical foundation of Innovation mechanism of the U.S. Chen Yunlan; Chen Yong; - "Heihe Journal"-2006-01-20

[4] The historical cause and social impact of the pragmatism thought of William James Gao Feng"Doctoral Thesis of Northeast Normal University"-2009-12-01 